\title{
Misdiagnosis of patients receiving inhaled therapies in primary care
}

This article was published in the following Dove Press journal: International Journal of Chronic Obstructive Pulmonary Disease 13 July 2010

Number of times this article has been viewed

\author{
José Luis Izquierdo' \\ Antonio Martín² \\ Pilar de Lucas $^{3}$ \\ José Miguel Rodríguez- \\ González-Moro 3 \\ Carlos Almonacid' \\ Alexandra Paravisini ${ }^{2}$ \\ 'Pneumology Department, University \\ Hospital of Guadalajara, ${ }^{2}$ Pfizer \\ Medical Department, ${ }^{3}$ Pneumology \\ Department, University Hospital \\ Gregorio Marañón, Madrid, Spain
}

Correspondence: José Luis Izquierdo Alonso S Neumología, Hospital Universitario, C/Donante de Sangre s/n 19002, Guadalajara, Spain Email jlizquierdo@sescam.org
Aim: To analyze the accuracy of diagnosis in a population receiving inhaled therapies due to respiratory diseases in a primary care setting.

Method: Noninterventional, multicenter, cross-sectional, observational epidemiologic study methodology.

Results: A total of 9752 subjects were evaluated. Of these, 4188 (42.9\%) patients were diagnosed with asthma, 4175 (42.8\%) with chronic obstructive pulmonary disease (COPD), and 1389 had a diagnosis of disease of unknown origin. Of those over the age of 40 years, 4079 (50.9\%) had COPD and 2877 (35.9\%) had asthma. Sixty percent of the subjects were men, and the proportion of men was higher in patients with COPD $(83.2 \%)$ than in the group with asthma (39.8\%, $P<0.0001)$. Of subjects with COPD, $17.3 \%$ had mild, $55.3 \%$ had moderate, $24.1 \%$ had severe, and $3.2 \%$ had very severe disease. With regard to the level of severity of asthma, $34.9 \%$ of subjects had intermittent, $34.6 \%$ had mild persistent, $27.1 \%$ had moderate persistent, and $3.5 \%$ had severe persistent disease. Only $13.9 \%$ of patients in the COPD group had all the characteristics of COPD based on the Global Initiative for Chronic Obstructive Lung Disease criteria and an absence of the characteristics of asthma.

Conclusions: The majority of patients receiving inhaled therapy in primary care did not have an accurate diagnosis according to current international guidelines for COPD and asthma. More initiatives for improving diagnostic accuracy in respiratory diseases must be implemented in primary care.

Keywords: respiratory disease, COPD, primary care, asthma, diagnosis

\section{Introduction}

Respiratory diseases that progress with obstruction of the respiratory tract are very prevalent in the community, giving rise to high health care costs. Asthma and chronic obstructive pulmonary disease (COPD) stand out in this group of diseases.

Asthma may affect individuals of any age. Although its prevalence varies from one country to another, it is estimated to be $1 \%-18 \%$ on a global level. The results from the European Community Respiratory Health Survey indicated that asthma rates in Spain are low, although they vary according to regions, with a range between $5 \%$ and $14.5 \% .{ }^{1}$ COPD mainly affects individuals over the age of 40 years. The Spanish IBERPOC study suggests that the prevalence of COPD in Spain is $9.1 \%$ for patients who are 40-69 years of age. ${ }^{2}$

In countries where patient monitoring is coordinated in primary care, as in Spain, an analysis of the situation at this level would provide valuable information on the impact that COPD and asthma has on the community and on the treatment needs of 
the population, regardless of the level of care, where the diagnosis is made, or whether there is additional follow-up in specialized health care services.

Asthma and COPD have certain similarities. Therefore, it is not easy to differentiate between them, especially in patients over the age of 40 years or those with spirometry that does not show complete reversibility of obstruction. Various studies have confirmed in both pathologies that there are problems of under-diagnosis, wrong diagnosis, a high percentage of patients with overlapping symptoms, and little observance of good clinical practice guidelines. The knowledge that the general population has about these diseases may also have an influence on health care needs and thus, on the diagnosis of one disease or the other. A population-based survey has shown a greater proportion of people who knew about asthma compared with those who knew about COPD (30\% versus $8.6 \%$, respectively). ${ }^{3}$

Given that both diseases are clearly different in their pathophysiology, different approaches to their treatment must be taken, despite certain features they may have in common. The excellent clinical response to inhaled corticosteroids (ICs) in asthma, and these agents are considered to be firstline treatment. In the case of COPD, the response to ICs is variable and when these are used, they are always a secondline treatment in combination with a bronchodilator. ${ }^{4-6}$ When more selective drugs are used (eg, leukotriene inhibitors), this difference becomes especially relevant. From a clinical point of view, the differential diagnosis between the two diseases holds interest beyond the purely theoretic, because their pathophysiologic basis, clinical evolution, and therapeutic strategies are different. ${ }^{7,8}$ Furthermore, knowing the characteristics of both disease processes in our population allows for the development of health strategies targeted to the needs of patients.

The objectives of this study were to analyze the accuracy of diagnosis in a population receiving inhaled therapies due to respiratory diseases in the primary care setting, to determine the diagnoses established by primary care physicians in this population, and to identify patient characteristics.

\section{Materials and methods Study design}

An observational, cross-sectional, multicenter, noninterventional, epidemiologic study was performed in patients attending primary health care facilities and being treated with inhalers. The investigators' decisions regarding health care or the medical treatment most appropriate for the patient did not have any influence on the methods used in the study. Because this was a cross-sectional, observational study, all data required for the assessment of endpoints included in the protocol were recorded during a single visit. The subjects participated in the study from 14 May 2008 to 26 November 2008. The project was approved by the Clinical Research Ethics Committee of the University Hospital of Guadalajara. All patients signed an informed consent form.

The study participants were selected by consecutively taking the first seven patients in a given practice population who were over the age of 18 years, met all the selection criteria (Table 1), and had attended a primary health care consultation. A total of 9931 subjects were recruited for the study by 1449 investigators.

Data collection was carried out using a standardized questionnaire including both clinical and functional variables. Bronchodilator tests were considered to be positive when baseline $\mathrm{FEV}_{1}$ increased by more than $200 \mathrm{~mL}$ and $12 \%$. Diagnosis was left to the investigator's judgment according to his/her routine clinical practice assuming that, according to published data, most of the patients would be diagnosed with COPD or asthma. Subsequently, the reliability of the diagnosis of asthma or COPD was assessed using GINA (Global Initiative for Asthma) ${ }^{9}$ and GOLD (Global Initiative for Chronic Obstructive Lung Disease $)^{10}$ criteria, respectively, as a reference in order to support one or other of the diagnoses, based on exposure to environmental risk factors, age and characteristics of symptom onset, previous history of atopy or asthma, and findings from spirometry. Bronchodilator tests were not used as a differentiation criterion, except in cases where a complete resolution of obstruction was confirmed. Patients not assigned by the physicians to asthma or COPD diagnosis groups were included for analysis purposes as a third group named "disease of unknown origin".

\section{Table I Selection criteria}

Inclusion criteria
- Patients aged $\geq 18$ years
- Patients in treatment with an inhaled drug (bronchodilator or inhaled
steroids)
- Patients who have signed the informed consent
Exclusion criteria
- Patients who have previously experienced an exacerbation of their
pulmonary disease within the last four weeks prior to the inclusion
visit
- Patients whose clinical history data were not available
- Patients having, at the time the study was performed, any serious
physical or mental impediment




\section{Statistical analysis}

It was initially agreed that a percentage of patients having a characteristic with a $95 \%$ confidence interval (CI) would be obtained for estimates of qualitative variables. A percentage of $50 \%$ was assumed in all the qualitative variables, because this percentage ensures a greater sample size, and therefore a better estimate. According to these considerations, the CI of $95 \%$ observed using normal distribution for large samples, at least 9500 individuals would need to be assessed in order to obtain a precision error of less than 1\%. Finally, with 9752 evaluable subjects, the CI of $95 \%$ using a normal distribution for large samples obtained a precision error not greater than $1 \%$.

The population used for the statistical analysis included patients who met all the selection criteria. If the case report forms were missing any information (not included by the investigator), the results were calculated using data from individuals who had these data. Therefore, the sample size varied for the different variables due to the amount of missing data. For each variable, the total number of subjects evaluated is superior to the sum of the number of evaluated patients diagnosed with asthma, COPD, or disease of unknown origin because 98 of 147 patients were diagnosed as having asthma and COPD together, so were not included in the analysis, and in other cases the investigators did not specify the diagnosis on the form.

Descriptive statistics of all the variables, including central tendency means and dispersion for all the quantitative variables, as well as relative and absolute frequencies for the qualitative variables, were performed with CIs of $95 \%$ in both cases. The distribution of the quantitative variables was studied and its adjustment to the Gaussian distribution was assessed using the Kolmogorov-Smirnov test. In order to compare independent data from more than two groups (among the different analysis groups), a one-way analysis of variance (ANOVA) was performed for the quantitative variables, as well as a Chi-square test for the qualitative variables. Statistical tests were performed with a $5 \%$ significance level and were bilateral. The $\mathrm{SAS}^{\circledR}$ version 8.2 statistical package was used for all statistical analyses.

\section{Results}

A total of 9931 individuals were included in the study, and $179(1.8 \%)$ were excluded because they did not meet the selection criteria, ie, 9752 (98.2\%) subjects were assessed and classified according to the type of diagnosis made by their physician. Of these, 4188 (42.9\%) patients were diagnosed with asthma, 4175 (42.8\%) with COPD, and 1389 had alternative diagnoses. One hundred and forty-seven patients were excluded because of a mixed diagnosis of asthma and
COPD or because the investigators did not specify a diagnosis on the form. Excluding these patients, 1242 (12.8\%) were classified as having disease of unknown origin. Of patients over the age of 40 years, 4079 (50.9\%) were diagnosed with COPD, 2877 (35.9\%) with asthma, and 13\% had alternative diagnoses.

Table 2 describes the demographic data and body mass index (BMI) of patients included in the study. Sixty percent were men, who comprised a higher percentage of patients diagnosed with COPD $(83.2 \%)$ than those with asthma (39.8\%; $P<0.001)$. The mean age (standard deviation [SD]) of patients with COPD was 67.2 (11.0), which was older than the age of asthma patients, ie, 50.1 (17.0) years $(P<0.0001)$. The average BMI was $27.2(4.3) \mathrm{kg} / \mathrm{m}^{2}$. Higher rates of excess weight and obesity were observed in patients diagnosed with COPD, and the percentage of patients who were underweight was low in all the groups.

As it can be seen in Table 3, 37.8\% of the population had never smoked, $37.2 \%$ were ex-smokers, and $24.9 \%$ were current smokers $(P<0.0001)$. The average number of years smoking was 28.2 (13.9). However, this was slightly higher at $22.6(12.5)$ years in patients diagnosed with COPD, and notably lower at $18.2(10.6)$ years in patients with an asthma diagnosis $(P<0.0001)$.

Using the British Medical Research Council dyspnea scale, $66.0 \%$ of the subjects had disease of unknown origin, $90.6 \%$ had COPD, and $65.1 \%$ had asthma and basal dyspnea (Figure 1).

Only 4379 (44.9\%) patients had spirometry performed, either prior to or during the study. Mean values (CI 95\%) of the $\mathrm{FEV}_{1} / \mathrm{FVC}$ postbronchodilator ratio were $75.8 \%$ (73.7-77.9), 66.5\% (65.3-67.6), and 76.9\% (75.7-78.1) in the disease of unknown origin, COPD, and asthma diagnosis groups, respectively $(P<0.0001)$. In these groups, $\mathrm{FEV}_{1}$ as a percentage of predicted was $77.4 \%(75.7-79.2), 60.6 \%$ (59.7-66.4), and 77.8\% (76.8-78.7). For the bronchodilator test, the average absolute change (CI 95\%) in $\mathrm{FEV}_{1}(\mathrm{~L})$ was $0.2(0.2-0.3)$ in the group with disease of unknown origin, $0.2(0.2-0.3)$ in the group with COPD, and $0.3(0.3-0.4)$ in the group with asthma $(P<0.0052)$. The change in percentage values, compared with baseline, was $10.2 \%$ (7.5-12.9), $15.9 \%(10.8-21.1)$, and $15.9 \%(13.2-18.1)$ in the three groups, respectively $(P=0.24)$.

According to the GOLD guidelines, as can be seen in Figure $2,17.3 \%$ of the subjects with a COPD diagnosis (based on spirometry data, $\mathrm{n}=1878$ ) had mild, $55.3 \%$ had moderate, $24.1 \%$ had severe, and $3.2 \%$ had very severe disease. With respect to severity levels in patients with asthma, according to GINA guidelines, $34.9 \%$ had intermittent, $34.6 \%$ had 
Table 2 Characteristics of the study population. The total number of subjects evaluated is greater than the sum of patients diagnosed with asthma, COPD, or disease of unknown origin, because of lack of inclusion of patients with both asthma and COPD and those for whom the investigators did not specify a diagnosis on the form are not included

\begin{tabular}{|c|c|c|c|c|c|}
\hline & Total & Unknown origin & COPD & Asthma & $P$-value \\
\hline \multicolumn{6}{|l|}{ Gender } \\
\hline$N$ & 9,480 & 1,209 & 4,068 & 4,068 & $<0.0001$ \\
\hline Male & $5692(60.0 \%)$ & $615(51.0 \%)$ & 3385 (63.2\%) & 1618 (39.8\%) & \\
\hline Female & $3788(40.0 \%)$ & $593(49.0 \%)$ & $683(16.8 \%)$ & 2450 (60.2\%) & \\
\hline \multicolumn{6}{|l|}{ Age (years) } \\
\hline $\mathrm{N}$ & 9,711 & $\mathrm{I}, 238$ & 4,157 & 4,174 & $<0.0001$ \\
\hline Average (SD) & $58.3(16.6)$ & $54.6(16.7)$ & $67.2(11.0)$ & $50,5(17,0)$ & \\
\hline $95 \% \mathrm{Cl}$ of average & $(53.0 ; 58.7)$ & $(53.7 ; 55.5)$ & $(66.9 ; 67.5)$ & $(50.0 ; 51.0)$ & \\
\hline Median (P25/P75) & $61.0(47.0 / 71.0)$ & $56.0(42.0 / 68.0)$ & $69.0(60.0 / 75.0)$ & $50.0(38.0 / 64.0)$ & \\
\hline \multicolumn{6}{|l|}{ BMI $\left(\mathrm{kg} / \mathrm{m}^{\prime}\right)$} \\
\hline $\mathrm{N}$ & 9,465 & 1,212 & 4,051 & 4,064 & $<0.0001$ \\
\hline Average (SD) & $27.2(4.3)$ & $26.5(4.1)$ & $28.1(4.2)$ & $26.5(4.4)$ & \\
\hline $95 \% \mathrm{Cl}$ of average & $(27.1 ; 27.3)$ & $(26.3 ; 26.8)$ & $(27.9 ; 28.2)$ & $(26.4 ; 26.7)$ & \\
\hline Median (P25/P75) & $26.8(24.3 / 29.5)$ & $26.2(23.8 / 28.7)$ & $27.7(25.4 / 30.4)$ & $26.1(23.6 / 28.9)$ & \\
\hline \multicolumn{6}{|c|}{ BMI classification according to the WHO* } \\
\hline $\mathrm{N}$ & 9.465 & 1,212 & 4,051 & 4,064 & $<0.0001$ \\
\hline Underweight & $108(1.1 \%)$ & $12(1.0 \%)$ & $36(0.9 \%)$ & $58(1.4 \%)$ & \\
\hline Normal weight & $2794(29.5 \%)$ & $440(36.3 \%)$ & $826(20.4 \%)$ & 1486 (36.6\%) & \\
\hline Overweight & 4450 (47.0\%) & $547(45.1 \%)$ & 2054 (50.7\%) & $1783(43.9 \%)$ & \\
\hline Chronic obesity & $1670(17.6 \%)$ & $174(14.4 \%)$ & 904 (22.3\%) & $568(14.0 \%)$ & \\
\hline Premorbid obesity & $345(3.7 \%)$ & $30(2.5 \%)$ & $83(4.5 \%)$ & $130(3.2 \%)$ & \\
\hline Morbid obesity & $98(1.0 \%)$ & $9(0.7 \%)$ & $48(1.2 \%)$ & $39(1.0 \%)$ & \\
\hline
\end{tabular}

*Underweight ( $\leq$ 18.5); Normal weight (I8.5-25); Overweight or class I obesity (25-30); Chronic obesity or class II obesity (30-35); Premorbid or class III obesity (35-40); Morbid obesity or class IV obesity $(\geq 40)$.

Abbreviations: $\mathrm{Cl}$, confidence interval; COPD, chronic obstructive pulmonary disease; BMI, body mass index; SD, standard deviation; WHO, World Health Organization.

persistent mild, $27.1 \%$ had moderate persistent, and $3.5 \%$ had severe persistent disease (Figure 3).

Table 4 shows the subjects' personal history of atopy, urticaria, eczema, and rhinitis. These diseases were more prevalent in asthma patients than in COPD patients $(P<0.0001)$. The proportion of subjects with allergies was also higher in subjects with asthma (41.4\%) than in those with COPD (11.3\%, $P<0.0001)$. A previous history of atopy and asthma symptoms were also more frequent in subjects with asthma $(P<0.0001)$; $81.7 \%$ had experienced episodes of wheezing, and this was lower in patients with COPD $(76.2 \%)$ than in patients with asthma (89.7\%, $P<0.0001)$; $48.8 \%$ had suffered chronic expectoration, being slightly lower in patients with asthma (21.9\%) and higher in patients with COPD $(79.4 \%, P<0.0001)$. However, apart from the normalization of post-bronchodilator pulmonary function, no other clinical parameter allowed for the establishment of a precise cut-off point in order to distinguish asthma from COPD. Therefore, only $13.9 \%$ of the patients in the COPD group showed, simultaneously, all the typical characteristics of COPD disease based on GOLD criteria and absence of typical asthma characteristics. In total, $36.7 \%$ of patients had previously been admitted to hospital at least once, and most of them were from the COPD group rather than the asthma group (51.4\% and $27 \%$, respectively, $P<0.0001$ ).

Table 3 Smoking among the different groups

\begin{tabular}{|c|c|c|c|c|c|}
\hline & Total & Unknown origin & COPD & Asthma & $P$-value \\
\hline \multicolumn{6}{|l|}{ Smoking } \\
\hline $\mathrm{N}$ & 9,711 & 1,238 & 4,159 & 4,173 & $<0.0001$ \\
\hline Never & 3,675 (37.8\%) & $576(46.5 \%)$ & $607(14.6 \%)$ & $2,436(58.4 \%)$ & \\
\hline Ex-smoker & 3,617 (37.2\%) & 321 (25.9\%) & $2,332(56.1 \%)$ & 921 (22.1\%) & \\
\hline Active & $2,419(24.9 \%)$ & 34 I (27.5\%) & I,220 (29.3\%) & $816(19.6 \%)$ & \\
\hline $\mathrm{N}$ & 4,883 & 531 & 2,935 & $\mathrm{I}, 344$ & $<0.0001$ \\
\hline Average (SD) & $31.5(24.5)$ & $24.5(20.0)$ & $39.5(24.7)$ & $17.0(16.1)$ & \\
\hline $95 \% \mathrm{Cl}$ of average & $(30.8 ; 32.2)$ & $(22.8 ; 26.2)$ & $(38.6 ; 40.4)$ & $(16.1 ; 17.8)$ & \\
\hline Median (P25/P75) & $27.0(15.0 / 42.0)$ & $20.0(10.0 / 32.0)$ & $35.0(22.5 / 50.0)$ & $12.0(5.3 / 22.5)$ & \\
\hline
\end{tabular}

Abbreviations: $\mathrm{Cl}$, confidence interval; COPD, chronic obstructive pulmonary disease; SD, standard deviation. 


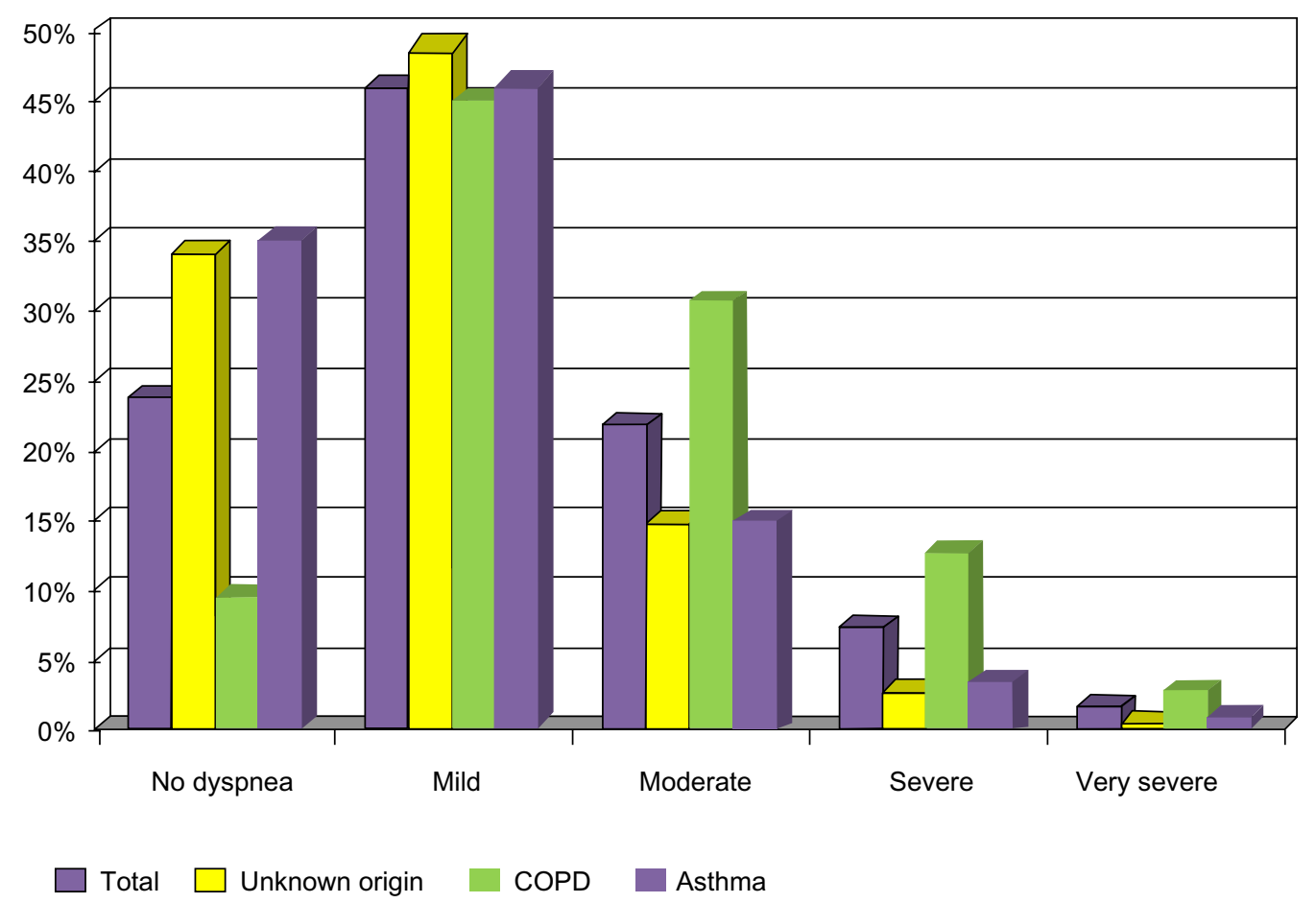

Figure I Severity of dyspnea in patients with diseases of unknown origin, chronic obstructive pulmonary disease, and asthma. Abbreviation: COPD, chronic obstructive pulmonary disease.

Table 5 shows active treatment at the time of evaluation. Given the study protocol, patients who were only being treated with antileukotrienes, theophylline, or maintenance oral corticosteroids were not assessed. In $46.5 \%$ of the subjects with disease of unknown origin, $62.1 \%$ of patients with COPD, and $60.9 \%$ of the patients with asthma, treatment comprised a fixed combination of long-acting beta ${ }_{2}$-adrenergic agonists and ICs, while $42.1 \%$ of subjects with disease of unknown origin, $43.7 \%$ of those with COPD, and $48.7 \%$ of those with asthma were taking short-acting beta ${ }_{2}$-adrenergic agents. A lower percentage of patients was receiving mucolytic medication (being higher in COPD patients), ICs, and long-acting anticholinergics. With regard to inhaled and noninhaled treatments, $28.9 \%$ and $28.3 \%$ of COPD patients were receiving two and three treatments, respectively, and $37.1 \%$ and $22.3 \%$ of those with asthma were taking two and three treatments, respectively (Table 6).

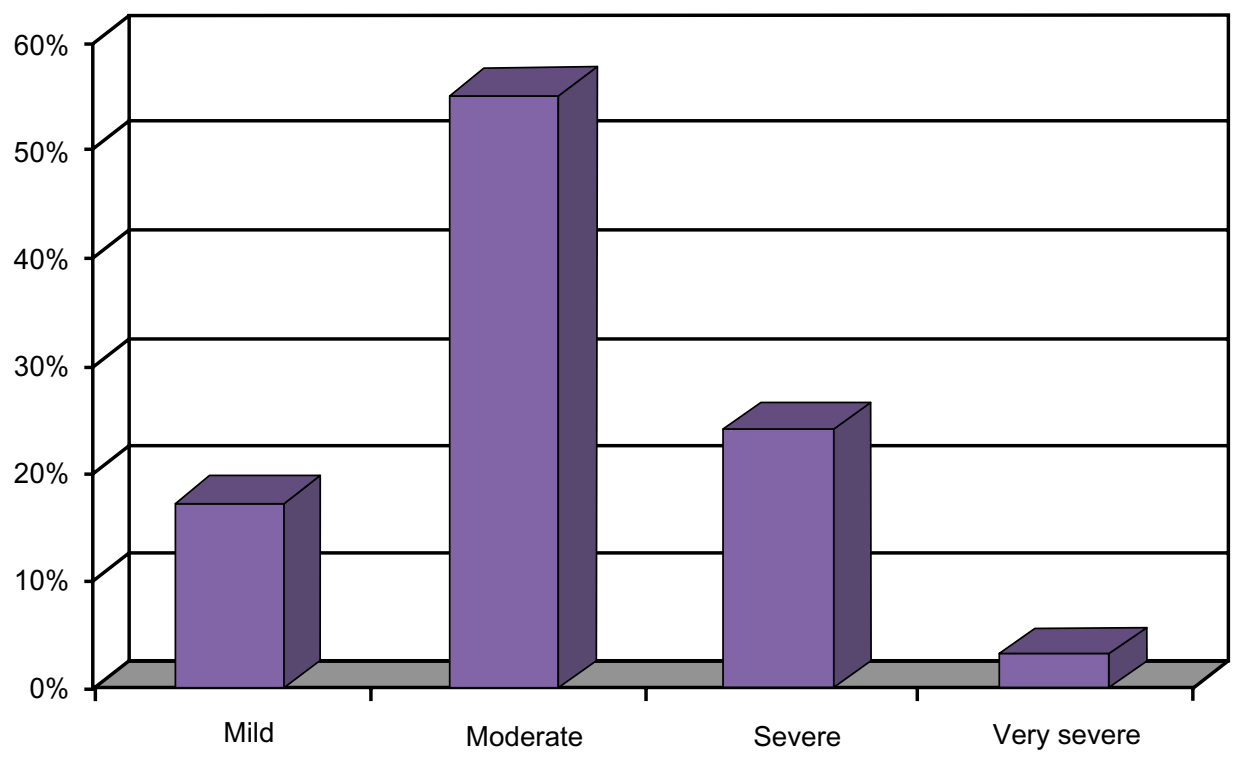

Figure 2 Chronic obstructive pulmonary disease severity according to Global Initiative for Chronic Obstructive Lung Disease classification. 


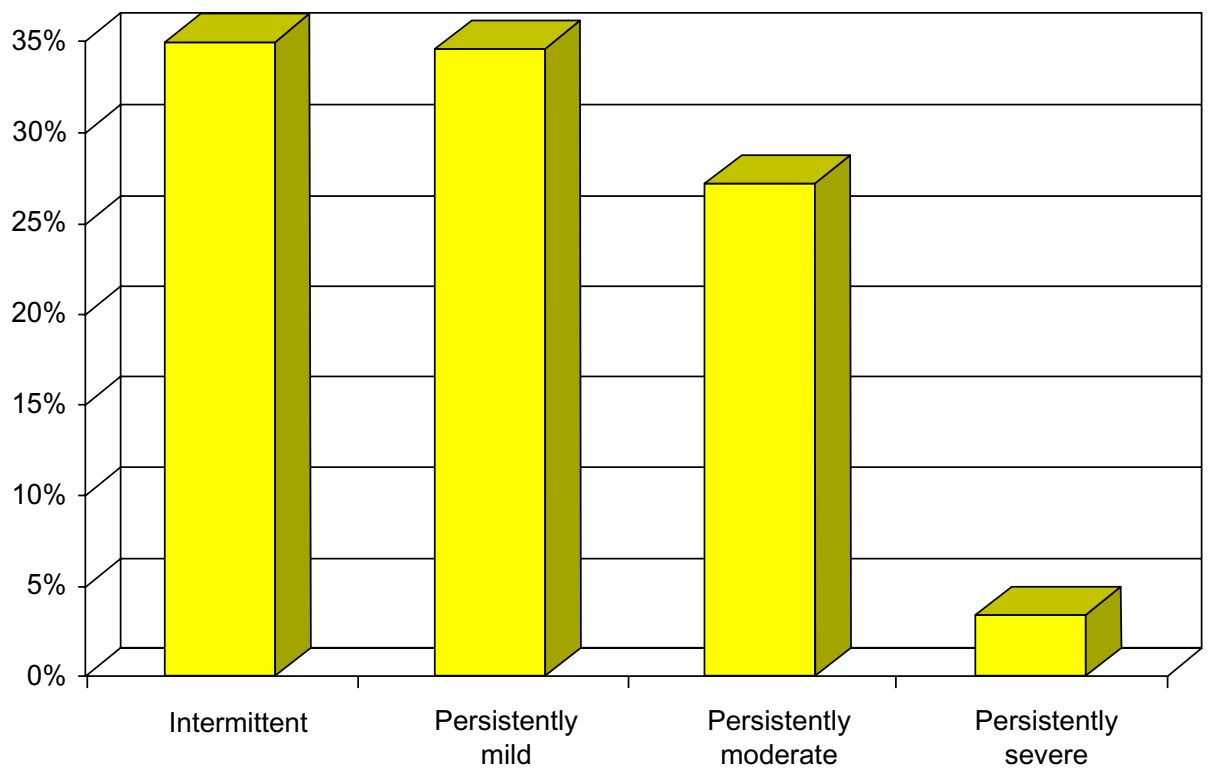

Figure 3 Asthma severity according to Global Initiative for Asthma classification.

\section{Discussion}

The results of this study provide clinical information regarding patients receiving inhaled therapies in primary care. At the same time we were able to analyze the main limitations for these diagnoses when we used international guidelines for the more frequent respiratory diseases seen in primary care, ie, asthma and COPD. The main difference between the asthmatic patients and those diagnosed with COPD is that there was a greater predominance of women, younger patients, lower baseline dyspnea, a different distribution of disease severity, and more symptoms of atopy, allergy, and rhinitis documented in asthma patients. These profiles meet the clinical characteristics for asthma and COPD according to the GINA and GOLD guidelines, respectively. However, because there is no gold standard that allows for confirmation of a correct diagnosis (unless obstruction of airflow is completely reversed), the proportion of wrong diagnoses could not be assessed for each disease group, because many patients do not fit a typical asthma or COPD profile.

The difficulty in making a differential diagnosis between the two diseases is already recognized as a significant clinical problem. In fact, in 1995, the American Thoracic Society stated that "it may be impossible to differentiate patients with asthma whose airflow obstruction does not remit completely from patients with chronic bronchitis and emphysema with a partially reversible obstruction and bronchial hyperreactivity". ${ }^{11}$

Cigarette smoking can be a confounding factor when attempting to diagnose asthma or COPD. In our study, the percentages of current smokers and ex-smokers among patients diagnosed with COPD and asthma were $85.4 \%$ and
$41.7 \%$, respectively. In another study recently performed in our community using a very large sample of women with a COPD diagnosis, $57.3 \%$ of patients stated that they had never smoked. This raises some doubts about the correct diagnosis of COPD and suggests the existence of other predisposing factors. ${ }^{12}$

One limitation of our study is that the diagnosis was based solely on the judgment of the physician caring for the patient. Therefore, reliability cannot be determined. Difficulty in making a diagnosis of asthma or COPD was more common in patients over the age of 40 years with chronic airflow obstruction. In these patients, differentiation between the two diseases must be made on clinical grounds, including all possible information in order to establish a diagnosis. In fact, although our series had more characteristics associated with asthma, such characteristics, in isolation, are not enough to differentiate accurately between the two diseases. In the population over the age of 40 years, $50.9 \%$ had a diagnosis of COPD, but only $13.9 \%$ of those patients had all the typical characteristics of COPD based on GOLD criteria and absence of all asthma characteristics at the same time. These data suggest that there could be a significant percentage of patients with an incorrect or unclear diagnosis. Tinkelman et al analyzed this problem in a population over the age of 40 years who were looked after in the primary care setting and had a prior diagnosis of COPD or were receiving treatment for COPD. Among subjects for whom COPD was "confirmed" through spirometry, $37.9 \%$ had a prior diagnosis of asthma and had no data showing chronic bronchitis or emphysema. ${ }^{13}$ However, this approach may not be valid, because a COPD diagnosis is assumed to be correct simply 
Table 4 Personal and family histories of asthma characteristics in the study population

\begin{tabular}{|c|c|c|c|c|c|}
\hline Personal history & Total & Unknown origin & COPD & Asthma & $P$-value \\
\hline \multicolumn{6}{|l|}{ Atopy } \\
\hline $\mathrm{N}$ & 9,412 & $\mathrm{I}, 207$ & 4,088 & 4,001 & $<0.0001$ \\
\hline No & $7,784(82.7 \%)$ & I,043 (86.4\%) & 3,888 (95.1\%) & 2,787 (69.7\%) & \\
\hline Yes & 1,628 (I7.3\%) & $164(13.6 \%)$ & $200(4.9 \%)$ & I,2। 4 (30.3\%) & \\
\hline \multicolumn{6}{|l|}{ Urticaria } \\
\hline $\mathrm{N}$ & 9,346 & $\mathrm{I}, 206$ & 4,081 & 3,955 & $<0.0001$ \\
\hline No & $7,9 \mid 4$ (84.7\%) & $\mathrm{I}, 047$ (86.8\%) & 3,801 (93.1\%) & $2,983(75.4 \%)$ & \\
\hline Yes & 1,432 (I5.3\%) & $159(13.2 \%)$ & $280(6.9 \%)$ & $972(24.6 \%)$ & \\
\hline \multicolumn{6}{|l|}{ Eczema } \\
\hline$N$ & 9,204 & 1,203 & 4,030 & 3,869 & $<0.0001$ \\
\hline No & 7,264 (78.9\%) & $936(77.8 \%)$ & $3,523(87.4 \%)$ & $2,729(70.5 \%)$ & \\
\hline Yes & $1,940(21.1 \%)$ & $267(22.2 \%)$ & $507(12.6 \%)$ & $\mathrm{I}, \mathrm{I} 40$ (29.5\%) & \\
\hline \multicolumn{6}{|l|}{ Rhinitis } \\
\hline $\mathrm{N}$ & 9,415 & 1,212 & 4,024 & 4,057 & $<0.0001$ \\
\hline No & 5,691 (60.4\%) & $776(64.0 \%)$ & $3,390(84.2 \%)$ & $\mathrm{I}, 475$ (36.4\%) & \\
\hline Yes & $3,724(39.6 \%)$ & $436(36.0 \%)$ & $634(15.8 \%)$ & $2,582(63.6 \%)$ & \\
\hline \multicolumn{6}{|l|}{ Known allergies } \\
\hline $\mathrm{N}$ & 9,302 & 1,179 & 3,996 & 4,013 & $<0.0001$ \\
\hline No & $6,972(75,0 \%)$ & $1,009(85.6 \%)$ & $3,545(88.7 \%)$ & $2,350(58.6 \%)$ & \\
\hline Yes & $2,330(25,0 \%)$ & $170(14.4 \%)$ & $451(11.3 \%)$ & $\mathrm{I}, 663(4 \mathrm{I} .4 \%)$ & \\
\hline \multicolumn{6}{|l|}{ Family history } \\
\hline \multicolumn{6}{|l|}{ Atopy } \\
\hline $\mathrm{N}$ & 9,244 & 1,189 & 4,045 & 3,897 & $<0.0001$ \\
\hline No & $8,018(86.7 \%)$ & I,057 (88.9\%) & 3,874 (95.8\%) & 3,014 (77.3\%) & \\
\hline Yes & $1,226(13.3 \%)$ & $132(11.1 \%)$ & $|7|(4.2 \%)$ & $883(22.7 \%)$ & \\
\hline \multicolumn{6}{|l|}{ Asthma } \\
\hline$N$ & 9,207 & 1,168 & 3,951 & 3,973 & $<0.0001$ \\
\hline No & 6,424 (69.8\%) & 920 (78.8\%) & $3,434(86.9 \%)$ & $2,013(50.7 \%)$ & \\
\hline Yes & $2,783(30.2 \%)$ & $248(21.2 \%)$ & $517(13.1 \%)$ & $1,960(49.3 \%)$ & \\
\hline
\end{tabular}

Abbreviation: COPD, chronic obstructive pulmonary disease.

when chronic air flow obstruction, defined as $\mathrm{FEV}_{1} / \mathrm{FVC}<70 \%$ is recorded. In other cases, even when introduction of multiple variables into the analysis (clinical, functional, and analytic variables) was attempted in the development of questionnaires, a precise diagnosis cannot be established in approximately $20 \%$ of patients. These patients frequently have a typical history of COPD and atopy or are ex-smokers with clinical characteristics of asthma. ${ }^{14-16}$ These data are similar to those presented in the National Health and Nutrition Examination Survey $\mathrm{III}^{17}$ where the degree of overlap ranged from $17 \%$ to $19.1 \%$.

Table 5 Treatment list (active at the time of assessment)

\begin{tabular}{|c|c|c|c|c|}
\hline & $\begin{array}{l}\text { Total } \\
\mathbf{N}=9,752 \\
\mathbf{N}(\%)\end{array}$ & $\begin{array}{l}\text { Unknown origin } \\
N=I, 242 \\
N(\%)\end{array}$ & $\begin{array}{l}\text { COPD } \\
N=4,175 \\
N(\%)\end{array}$ & $\begin{array}{l}\text { Asthma } \\
N=4,188 \\
N(\%)\end{array}$ \\
\hline Fixed combination LABA/IC & $5,794(59.4 \%)$ & $576(46.6 \%)$ & $2,592(62.1 \%)$ & $2,550(60.9 \%)$ \\
\hline Short-acting beta- 2 adrenergic agents & $4,437(45.5 \%)$ & $523(42.1 \%)$ & $1,823(43.7 \%)$ & $2,038(48.7 \%)$ \\
\hline Mucolytic medication*** & $2,755(28.3 \%)$ & $319(25.7 \%)$ & $\mathrm{I}, 69 \mathrm{I}(40.5 \%)$ & $705(16.8 \%)$ \\
\hline Inhaled corticoids (IC) & $2,402(24.63 \%)$ & $269(21.7 \%)$ & $\mathrm{I}, 016(24.3 \%)$ & $\mathrm{I}, 07 \mathrm{I}(25.6 \%)$ \\
\hline Long-acting anticholinergics & $2,258(23.2 \%)$ & $14 \mid(\mid 1.4 \%)$ & $1,693(40.6 \%)$ & $374(8.9 \%)$ \\
\hline $\begin{array}{l}\text { Long-acting beta-2 adrenergic } \\
\text { agonists (LABA) }\end{array}$ & 1,939 (19.9\%) & $200(16.1 \%)$ & $1,006(24.1 \%)$ & $700(16.7 \%)$ \\
\hline Antileukotrienes** & $\mathrm{I}, 455$ (I4.9\%) & $107(8.6 \%)$ & $328(7.9 \%)$ & 987 (23.6\%) \\
\hline Short-acting anticholinergics & $907(9.3 \%)$ & $83(6.7 \%)$ & $565(13.5 \%)$ & $245(5.9 \%)$ \\
\hline Theophylline*** & $758(7.8 \%)$ & $43(3.5 \%)$ & $532(12.7 \%)$ & $168(4.0 \%)$ \\
\hline Maintentance oral corticoids** & $642(6.6 \%)$ & $37(3.0 \%)$ & $420(10.1 \%)$ & $172(4.1 \%)$ \\
\hline Other non-inhaled agents & $361(3.7 \%)$ & $37(3.0 \%)$ & $121(2.9 \%)$ & $200(4.8 \%)$ \\
\hline Other inhaled agents & I (0.0\%) & $\mathrm{I}(0.1 \%)$ & $0(0.0 \%)$ & $0(0.0 \%)$ \\
\hline
\end{tabular}

Notes: ***Certain patients were taking more than one treatment; **Maintentance oral corticoids refers to the use of this drug at the moment of the study. Abbreviations: COPD, chronic obstructive pulmonary disease; IC, inhaled corticosteroids, LABA, long-acting beta ${ }_{2}$-adrenergic agonists. 
Table 6 Number of inhaled and noninhaled treatments that each patient received

\begin{tabular}{|c|c|c|c|c|c|}
\hline & Total & Unknown origin & COPD & Asthma & $P$-value \\
\hline \multicolumn{6}{|c|}{ Number of inhaled and non-inhaled treatments } \\
\hline$N$ & 9,676 & 1,223 & 4,159 & 4,153 & $<0.0001$ \\
\hline I & 2,409 (24.9\%) & $526(43.2 \%)$ & $662(15.9 \%)$ & I, 199 (28.9\%) & \\
\hline 2 & $3,211(33.2 \%)$ & 415 (33.9\%) & I,200 (28.8\%) & I,540 (37.1\%) & \\
\hline 3 & $2,313(23.9 \%)$ & 177 (14.5\%) & I, I 76 (28.3\%) & 925 (22.3\%) & \\
\hline 4 & 1,059 (10.9\%) & $78(6.4 \%)$ & $626(15.1 \%)$ & 339 (8.2\%) & \\
\hline 5 & 464 (4.3\%) & 17 (1.4\%) & $332(8.0 \%)$ & $106(2.6 \%)$ & \\
\hline+5 & $220(2.3 \%)$ & $8(0.7 \%)$ & $163(3.9 \%)$ & $44(1.1 \%)$ & \\
\hline
\end{tabular}

Abbreviation: COPD, chronic obstructive pulmonary disease.

In view of the lack of good clinical and/or analytic parameters that make it possible to differentiate between these two diseases, it has become common to use the bronchodilator test, both in daily clinical practice and in clinical trials. Therefore, many authors interpret a positive bronchodilator test as being synonymous with asthma. However, Anthonisen et $\mathrm{al}^{18}$ demonstrated that a large number of patients diagnosed with COPD showed a positive response if the test is repeated, and more than $60 \%$ show at least one positive response when a series of consecutive bronchodilator tests are performed.

Recently, the UPLIFT (Understanding Potential Longterm Impacts on Function with Tiotropium) study has confirmed these results, ie, more than $50 \%$ of COPD patients had a positive bronchodilator response. ${ }^{19}$ Even though the GOLD guidelines state that a positive response occurs with an increase of $200 \mathrm{~mL}$ or a $12 \%$ increase in $\mathrm{FEV}_{1}$ compared with baseline, this criterion varies notably in different series and clinical guides, with ranges varying from $10 \%$ to $20 \%$. In practice, none of these rates show acceptable levels of reproducibility, and the bronchodilator test cannot be seen as a dichotomous variable confirming or denying a diagnosis. That is the reason why the bronchodilator test distinguishes asthma from COPD so poorly. Thus, unless the disappearance of the obstruction is confirmed, this test should not be used to make a differential diagnosis between the two diseases. ${ }^{208-22}$ In spite of the frequency with which a limit of $15 \%$ has been indicated in order to determine a diagnosis of asthma or "asthmatic bronchitis", this is the average value of functional improvement obtained by Anthonisen in a group of COPD patients, in which an asthma diagnosis was considered to be an exclusion criterion. ${ }^{18}$ It should be noted that the $15 \%$ increase in $\mathrm{FEV}_{1}$ obtained in the bronchodilator test was documented in both the asthma and COPD groups, with no significant differences between them.

Although the asthma prevalence was similar to that of COPD in this large series of patients, there are significant differences in the severity of both diseases, in that $69.5 \%$ of asthma patients had intermittent or persistent mild disease, whereas $82 \%$ of COPD patients had moderate or severe disease. Even though the criteria used to assess the severity of both diseases are different, these data can justify the existence of a greater basal clinical repercussion, with dyspnea levels being significantly higher in COPD patients.

Use of spirometry in the primary health care setting remains low, and was performed in only $50 \%$ of the population treated with bronchodilator medication. Another limitation of our study is that functional confirmation of COPD was only possible in $44.9 \%$ of the patients who had had spirometry in response to a bronchodilator test, which could have influenced our results. In a previous study, $26.5 \%$ of patients assessed in primary health care were diagnosed with COPD although they had had no spirometry test or functional report that could aid the diagnosis and establish disease severity. Our results are very similar to those of other epidemiologic studies. Women and nonsmoking patients were less likely to have spirometry done. However, multivariate analysis did not show any effect of gender or smoking on whether or not spirometry was performed. ${ }^{23}$

The pharmacologic prescription pattern was similar between the two diseases, with the exception of a greater use of tiotropium and mucolytic agents in COPD and a greater use of leukotriene antagonists in asthma. Given that bronchodilators and ICs are the most common treatments for asthma and COPD, not surprisingly the prescription profile is similar in both cases. Unfortunately, it was not possible to obtain information regarding the doses used or the consumption per year. This information would have helped to determine the consumption profile of these drugs in both disease groups in order to determine if they were temporary or permanent prescriptions. The greater use of mucolytic agents, tiotropium, and theophylline in COPD patients is also not surprising. However, the significant consumption of leukotriene antagonists in COPD patients is notable, given their lack of efficacy in this disease. These data are consistent with the findings of other observational studies performed in this setting. ${ }^{24-26}$ 
In conclusion, the majority of patients in our study who were receiving inhaled therapy in primary care did not have an accurate diagnosis according to current international guidelines for COPD or asthma. The percentage of patients diagnosed with asthma or COPD was similar, although there were relevant differences in gender, age, and clinical characteristics. More initiatives for improving diagnosis accuracy in respiratory diseases must be implemented in primary care, and focusing on use of spirometry. Improving the differential diagnosis in primary care will improve the management of these common respiratory diseases and ultimately improve the health care of affected patients.

\section{Disclosure}

AM is an employee of Pfizer. The other authors did not have any conflicts of interest at the time the study was conducted.

\section{References}

1. Janson C, Anto J, Burney P, et al. The European Community Respiratory Health Survey: What are the main results so far? European Community Respiratory Health Survey II. Eur Respir J. 2001;18:598-611.

2. Sobradillo PV, Miravitlles M, Gabriel R, et al. Geographic variations in prevalence and underdiagnosis of COPD: Results of the IBERPOC multicentre epidemiological study. Chest. 2000;118:981-989.

3. Miravitlles M, de la Roza C, Morera J, et al. Chronic respiratory symptoms, spirometry and knowledge of COPD among the general population. Respir Med. 2006;100:1973-1980.

4. Bateman ED, Hurd SS, Barnes PJ, et al. Global strategy for asthma management and prevention: GINA executive summary. Eur Respir J. 2008;31:143-178.

5. Rabe KF, Hurd S, Anzueto A, et al. Global strategy for the diagnosis, management, and prevention of chronic obstructive pulmonary disease: GOLD executive summary. Am J Respir Crit Care Med. 2007;176: 532-555.

6. Peces-Barba G, Barberà JA, Agustí A, et al. Diagnosis and management of chronic obstructive pulmonary disease: Joint guidelines of the Spanish Society of Pulmonology and Thoracic Surgery (SEPAR) and the Latin American Thoracic Society (ALAT). Arch Bronconeumol. 2008; 44:271-281.

7. Barnes PJ. Mechanisms in COPD: Differences from asthma. Chest. 2000:117:S10-S14.

8. Juniper EF, Kline PA, Vanzieleghem MA, Ramsdale EH, O'Byrne PM, Hargreave FE. Effect of long-term treatment with an inhaled corticosteroid (budesonide) on airway hyperresponsiveness and clinical asthma in nonsteroid-dependent asthmatics. Am Rev Respir Dis. 1990; 142:832-836

9. GINA. Global Strategy for Asthma Management and Prevention, 2006. NHI Publications No 02-3659. GINA update 2008. Available from: http://www.ginasthma.org. Accessed on 2010, June 22.
10. Global Strategy for the Diagnosis, Management and Prevention of Chronic Obstructive Pulmonary Disease (Updated 2008). Available from: http://www.goldcopd.org. Accessed on 2010, June 22.

11. American Thoracic Society. Standards for the diagnosis and care of patients with chronic obstructive pulmonary disease. Am J Respir Crit Care Med. 1995;152:S77-S121.

12. Rodríguez-González J, Izquierdo JL, Antón E, de Lucas P, Martín A; MUVICE Study Group. Health-related quality of life in outpatient women with COPD in daily practice: The MUVICE Spanish study. Respir Med. 2009;103:1303-1312.

13. Tinkelman DG, Price DB, Nordyke RJ, Halbert RJ. Misdiagnosis of COPD and asthma in primary care patients 40 years of age and over. J Asthma. 2006;3:75-80.

14. Bellia V, Battaglia S, Catalano F, et al. Aging and disability affect misdiagnosis of COPD in elderly asthmatics: The SARA study. Chest. 2003; 123:1066-1072.

15. Tinkelman DG, Price DB, Nordyke RJ, et al. Symptom-based questionnaire for differentiating COPD and asthma. Respiration. 2006; 73:296-305.

16. Beeh KM, Kornmann O, Beber J, Ksoll M, Buhl R. Clinical application of a simple questionnaire for the differentiation of asthma and chronic obstructive pulmonary disease. Respir Med. 2004;98:591-597.

17. Soriano JB, Davis KJ, Coleman B, Visick G, Mannino D, Pride NB. The proportional Venn diagram of obstructive lung disease: Two approximations from the United States and the United Kingdom. Chest. 2003; 124:474-481.

18. Anthonisen NR, Wright EC; and the IPPB Trial Group. Bronchodilator response in chronic obstructive pulmonary disease. Am Rev Respir Dis. 1986;133:814-819.

19. Tashkin DP, Celli B, Decramer M, et al. Bronchodilator responsiveness in patients with COPD. Eur Respir J. 2008;31:742-750.

20. Meslier N, Racineux JL, Six P, Lockhart A. Diagnostic value of reversibility of chronic airway obstruction to separate asthma from chronic bronchitis: A statistical approach. Eur Respir J. 1989;2: 497-505.

21. Kesten S, Rebuck A. Is the short term response to inhaled betaadrenergic agonist sensitive or specific for distinguishing between asthma and COPD? Chest. 1994;105:1042-1045.

22. Paré D, Wiggs BJ. Baseline airway caliber. A confounder in interpreting bronchoconstriction and bronchodilatation. Chest. 1989;5: 964-965.

23. de Miguel Díez J, Izquierdo Alonso JL, Molina París J, Rodríguez González-Moro JM, de Lucas Ramos P, Gaspar Alonso-Vega G. Reliability of chronic obstructive pulmonary disease diagnosis by primary care physicians and pneumologists in Spain. Predictive factors. Arch Bronconeumol. 2003;39:203-208.

24. Izquierdo JL. The burden of COPD in Spain: Results from the Confronting COPD Survey. Respir Med. 2003;97:A61-A67.

25. Izquierdo Alonso JL, Rodríguez González-Moro JM, de Lucas Ramos P, Martín Centeno A, Gobartt Vázquez E. Has the treatment of COPD changed in Spain? Results of a community multicenter study (VICE). Rev Clin Esp. 2008;208:18-25.

26. Izquierdo JL, De Miguel J. Economic impact of pulmonary drugs on direct costs of stable chronic obstructive pulmonary disease. COPD. 2004;1:215-223.
International Journal of COPD

\section{Publish your work in this journal}

The International Journal of COPD is an international, peer-reviewed journal of therapeutics and pharmacology focusing on concise rapid reporting of clinical studies and reviews in COPD. Special focus is given to the pathophysiological processes underlying the disease, intervention programs, patient focused education, and self management protocols.

\section{Dovepress}

This journal is indexed on PubMed Central, MedLine and CAS. The manuscript management system is completely online and includes a very quick and fair peer-review system, which is all easy to use. Visit http://www.dovepress.com/testimonials.php to read real quotes from published authors. 